\title{
The association of cobalt with iron and manganese (oxyhydr)oxides in marine sediment
}

\author{
Anthony Stockdale · William Davison · Hao \\ Zhang* · John Hamilton-Taylor
}

This is a pre-print version

The published version is available at: http://dx.doi.org/10.1007/s10498-010-9092-1

\begin{abstract}
Formation and dissolution of authigenic Fe and Mn (oxyhydr)oxides influence cycling of trace metals in oxic/suboxic surface sediments. We used the diffusive gradients in thin films technique (DGT) to estimate the association of cobalt with iron and manganese oxides. We compared $\mathrm{Co}, \mathrm{Fe}$ and $\mathrm{Mn}$ maxima measured by DGT in the pore waters of fresh and aged marine sediment cores and estimated the $\mathrm{Co} / \mathrm{Fe}$ and $\mathrm{Co} / \mathrm{Mn}$ ratios in the metal oxides. A Mn maximum was not visible in DGT concentration profiles of freshly collected sediment cores, but after ageing the sediment we observed a distinct Mn peak, presumably due to broadening of the depth range over which the various electron acceptors occur. Estimated $\mathrm{Co} / \mathrm{Mn}$ ratios from both experiments are within the range of literature values for marine sediments, but the value from the aged experiment is at the lower end of the range. This is attributed to stimulation of sulphate reduction and precipitation of cobalt sulfides. The good correlation between Co and Fe maxima in the fresh sediments is attributed to the similarity of their reactions with sulphide rather than Co being released during authigenic Fe oxide reduction.
\end{abstract}

Keywords DGT $\cdot$ porewater $\cdot$ trace metal $\cdot$ early diagenesis

Department of Environmental Science, Lancaster Environment Centre (LEC), Lancaster University, Lancaster, LA1 4YQ, United Kingdom

Hao Zhang

Tel.: +44 (0)1524 593899

Fax: +44 (0)1524 593985

E-mail: h.zhang@lancaster.ac.uk

Present address of: A. Stockdale; Centre for Ecology and Hydrology, Lancaster Environment Centre,

Lancaster, LA1 4YN, United Kingdom 


\section{Introduction}

Iron and manganese oxyhydroxides formed within the oxic surface layers of sediment may play an important role in the regulation of trace element concentrations and their vertical distribution in sediments (Douglas and Adeney, 2000). Oxygenic oxidation of $\mathrm{Mn}(\mathrm{II})$ is slow, allowing it to diffuse through the oxic-anoxic interface, thus enabling formation of Mn-oxides within the oxic zone (Taillefert et al, 2002) and potentially also in the overlying water. A faster oxidation rate limits the $\mathrm{Fe}$ (II) that can exist within this zone. These processes were shown distinctly in experiments undertaken by Petersen et al (1995). As the authigenic oxides form, they regulate the flux of trace elements into the overlying water (Douglas and Adeney, 2000), via coprecipitation and adsorption mechanisms. Co is released to porewaters within the zone of manganese reduction, and recycled between oxic and sub-oxic sediments and porewaters (Heggie and Lewis, 1984). Within both marine and freshwater sediments, profiles of $\mathrm{Mn}$ (II) have been shown to be closely correlated with those of cobalt (e.g. Zhang et al, 2002; Shuttleworth, 1999). Many studies have shown the linkage between the elements within water columns affected by anoxia (e.g. Balistrieri et al, 1994; Taillefert et al, 2002; Hamilton-Taylor et al, 2005).

As Mn and Fe oxyhydroxides (plus associated trace elements) form within the oxic zone they can accumulate, via accretion, on the surface of Teflon strips inserted into sediments. This method has been used to study the relationship between these authigenic oxides and trace element cycling within freshwater (Tessier et al, 1996) and marine environments (Douglas and Adeney, 2000, estuarine sediment). Where discrete layers of $\mathrm{Mn}$ and $\mathrm{Fe}$ oxyhydroxides form they can be analysed independently (Tessier et al, 1996).

The diffusive gradients in thin-films (DGT) technique has been used in both freshwater and marine environments to assess the flux of the reduced forms of metals to the device. DGT measures directly the flux of metal from the sediment during the deployment time, which reflects the concentration in the porewater, its diffusional transport and the supply from the solid phase to solution. It can be interpreted simply as the average porewater concentration at the interface of the device over the deployment period. Using this technique several studies have revealed close relationships between DGT measured Mn and Co (e.g. Zhang et al, 2002; Fones et al, 2004).

Here we present a novel use of DGT to examine the association of cobalt with $\mathrm{Fe}$ and $\mathrm{Mn}$. We compare Co, Fe and Mn maxima measured by DGT from deployments in fresh and aged marine sediments and estimate the ratios of Co associated with the oxides of Fe and Mn. Ageing and homogenization of one of the sediment samples was undertaken to reduce the concentration of reactive organic matter in the surface sediments. This effectively increased the depth range over which the different electron acceptors are dominant and resulted in distinct maxima of all three metals. 


\section{Materials and methods}

\subsection{Sampling and experimental setup}

The marine sediment used for this experiment was collected, using a Jenkin corer (Blomqvist, 1985), from Fleetwood Marina (UK). The site is described more fully by Naylor et al (2004). Sediment for the aged/homogenised and the intact core experiments were collected in March 2006 and November 2007 respectively. For the aged sediment experiment, after retrieval the sediment and overlying water were thoroughly homogenised and placed in a glass aquarium tank to settle. Once the sediment had settled, overlying water was circulated across it in a smooth flow using a pump, and trickle devices. Initially this water was bubbled with nitrogen gas for $\sim 3$ days to reduce populations of benthic fauna. Following this treatment, circulation was maintained to provide oxic overlying water and to avoid a thick diffusive boundary layer. The sediment was then left to age for approximately eight months at room temperature $\left(20 \pm 2^{\circ} \mathrm{C}\right)$ before the DGT deployments commenced. For the second part of the experiment, intact cores were incubated at approximately the in situ temperature $\left(\sim 11^{\circ} \mathrm{C}\right)$. Cores, collected in $50 \mathrm{~cm}$ tubes, were extruded into shorter tubes $(\sim 13 \mathrm{~cm})$ so that only sediment was contained in the tubes, thus allowing water flow over the sediment surface. Overlying water was circulated through the aquarium containing the cores to simulate some features of the in situ conditions. The DGT devices were deployed approximately one week after sample collection.

\subsection{DGT preparation and deployment}

DGT planar sediment probes (dgtresearch.com) were prepared using two types of polyacrylamide gel. The back layer comprised a gel containing the binding phase resin, Chelex-100, and the top layer was a $0.8 \mathrm{~mm}$ thick hydrogel. These were prepared according to procedures described elsewhere (e.g. Naylor et al, 2004). The top gel layer was covered with a $0.14 \mathrm{~mm}$ thick filter membrane $(0.45 \mu \mathrm{m}$ pore size; Pall Corporation), giving a total diffusive layer thickness $(\Delta g)$ of $0.94 \mathrm{~mm}$. Prior to deployment all probes were deoxygenated for 24 hours by submerging in ultrapure water (Millipore MQ; $18.2 \mathrm{M} \Omega \mathrm{cm}$ ) through which oxygen free nitrogen gas was continuously bubbled.

\subsection{Experimental and sample processing procedures}

Multiple probes were deployed simultaneously at the beginning of each experiment ( 2 probes per core) and were removed at fixed time intervals to give total deployment times of 4 to 24 hours. Replicate probes were retrieved at different times to check that there was no interference to the DGT signal caused by the insertion of the probe, such as channelling or smearing. These effects will tend to have more influence at shorter deployment times, as the probe will soon (minutes to hours) assume the conditions of the local sediment (Tankere-Muller et al, 2007). Upon retrieval the 
DGT probes were thoroughly rinsed with MQ water, before refrigerated storage in clean plastic bags. Deployed gels were sliced into $5 \mathrm{~mm}$ squares using a Teflon coated razor blade mounted on a micromanipulator with vernier scale. The procedure gave three replicates for each depth interval and these are represented by error bars in the figures of the data. For each probe, results were obtained for 17 depth intervals covering $90 \mathrm{~mm}$. Sliced gel pieces were eluted in $0.5 \mathrm{~mL}$ of $1 \mathrm{M}$ nitric acid (BDH, Aristar grade) in closed micro-vials for a minimum of 24 hours. Samples were diluted by a factor of five before analysis by inductively coupled plasma-mass spectrometry (ICP-MS; Thermo Electron X-Series) using Rh as an internal standard. This overall procedure minimises the seawater matrix.

\subsection{Data analysis}

A concentration gradient through the DGT diffusive layers (hydrogel and filter membrane) is established by immobilisation of analytes in the binding layer and resupply from the porewaters at the device interface. The mass of solute accumulated in the binding gel $(M)$ per unit area $\left(A, \mathrm{~cm}^{2}\right)$ divided by the deployment time $(t, \mathrm{~s})$, gives the time-averaged solute flux $(F)$ through the diffusive layer (typical units $\mathrm{mol} \mathrm{cm} \mathrm{cm}^{-2}$ $\mathrm{s}^{-1}$, Eqn. 11).

$$
F=M / A t
$$

DGT utilises Fick's Law of diffusion to determine the time averaged concentrations at the probe-sediment interface $\left(C_{\mathrm{DGT}}\right)$ from the mass of analyte on the binding layer (Eqn. 2. where $D_{\mathrm{d}}$ is the diffusion coefficient in the gel).

$$
F=D_{\mathrm{d}} C_{\mathrm{DGT}} / \Delta g
$$

Combining Eqns. 1 and 2 allows calculation of $C_{\text {DGT }}$ (Eqn. 3, Zhang et al, 1998, where $f_{\mathrm{e}}$ is the elution efficiency of the Chelex gel).

$$
C_{\mathrm{DGT}}=\frac{M \Delta g}{D_{\mathrm{d}} A t f_{\mathrm{e}}}
$$

In well stirred solutions $C_{\mathrm{DGT}}$ can be considered to be representative of the aqueous concentration. However, in porewaters $C_{\mathrm{DGT}}$ represents the average concentration at the surface of the device over the deployment period. It only represents the unperturbed porewater concentration when resupply from the solid phase acts as a sufficient buffer. As resupply is unlikely to be sufficient to buffer the porewater, the interfacial concentrations are controlled by varying contributions from the following factors: diffusion, the solid phase pool size and associated desorption kinetics, and active remobilisation processes. Theoretical cases of different DGT resupply scenarios have been investigated in several studies (e.g. Harper et al, 1998; Zhang et al, 2002). Where a DGT probe detects a redox boundary (i.e. where Fe(II) or Mn(II) show distinct maxima) any associated trace element maxima can be assumed to be largely due to release of the trace component from the source authigenic oxide as it is utilised as an electron acceptor. Trace metal release solely from organic matter $(\mathrm{OM})$ as it degrades, is much lower than the concomitant release from authigenic oxides if they are the 
electron acceptor (e.g., Naylor et al, 2004). Where Fe and Mn peaks do not overlap, the ratios of trace element to solute $\mathrm{Mn}$ or Fe may give an estimate of the molar ratio associated with each authigenic oxide.

\section{Results and discussion}

3.1 Effects of the sediment ageing and general observations from the profiles

In an intact sediment in an environment without resuspension events, concentration profiles of reactive organic matter and Fe/Mn (oxyhydr)oxides generally decrease with depth. Collection of the sediment with a Jenkin corer retains intact profiles throughout the depth of the sampled core (typically $13 \mathrm{~cm}$ at Fleetwood Marina). When homogenised and allowed to resettle, the reactive organic matter within the surface sediment will be lower in concentration due to averaging of the profiles. This results in oxidants being dominant over a greater depth range, as their consumption is directly related to the $\mathrm{OM}$ concentration. Conversely, increasing the reactive organic matter at depth may increase sulphide production, as sulphate will be the primary electron acceptor (EA) when the reactive Fe/Mn (oxyhydr)oxides fall below the concentration where they are the dominant electron acceptor. This elevated sulphide production may bring about additional removal of metals via sulphide precipitation. Ageing of the sediment further reduces the reactive $\mathrm{OM}$ and increases the depth range over which individual oxidants are utilised as the electron acceptor. This was observed visually during the experiment where the light coloured oxic zone increased in depth over the ageing period.

Mean DGT concentrations for each depth are shown in Figures 1) (freshly collected sediment) and 2 (aged sediment), for deployments up to a 24 hour period. Additional probes were deployed for periods longer than 24 hours. However, at deployment times of 36 hours or more competition effects were observed, where $\mathrm{Mn}$ is displaced from the binding phase by Fe (this work, unpublished results).

As resupply of solutes to the device interface is not fully sustained, the data generally show a decrease in the magnitude of $C_{\text {DGT }}$ as the deployment time is increased. However, some of the maximum peak values are observed at $8 \mathrm{hrs}$ rather than $4 \mathrm{hrs}$. This may be due to complexes of the metals with slower diffusion coefficients (Scally et al, 2006) and/or binding of metals to diffusive gel (Garmo et al, 2008), increasing the time required for a steady state to be reached. Multiple DGT deployments in soils have shown peak $\mathrm{C}_{\text {DGT }}$ values at deployment times of 8 to 10 hrs (Ernstberger et al, 2002), which may be attributable to these effects.

Some variability in the profiles is to be expected, as there may be heterogeneity in the sediment (cores were collected within an area of approximately 100 square meters), or the coring device may introduce some minor inconsistencies between the cores (Blomqvist, 1985). Heterogeneity is likely to affect the intact sediment cores to a greater degree than the homogenised sediment. The differences in the Mn structure in the intact core deployments (Fig. 1) are attributed to this factor. Alternative explanations include smearing of sediment across the probe face during insertion or heterogeneity in the resin distribution within the binding phase gel. The 


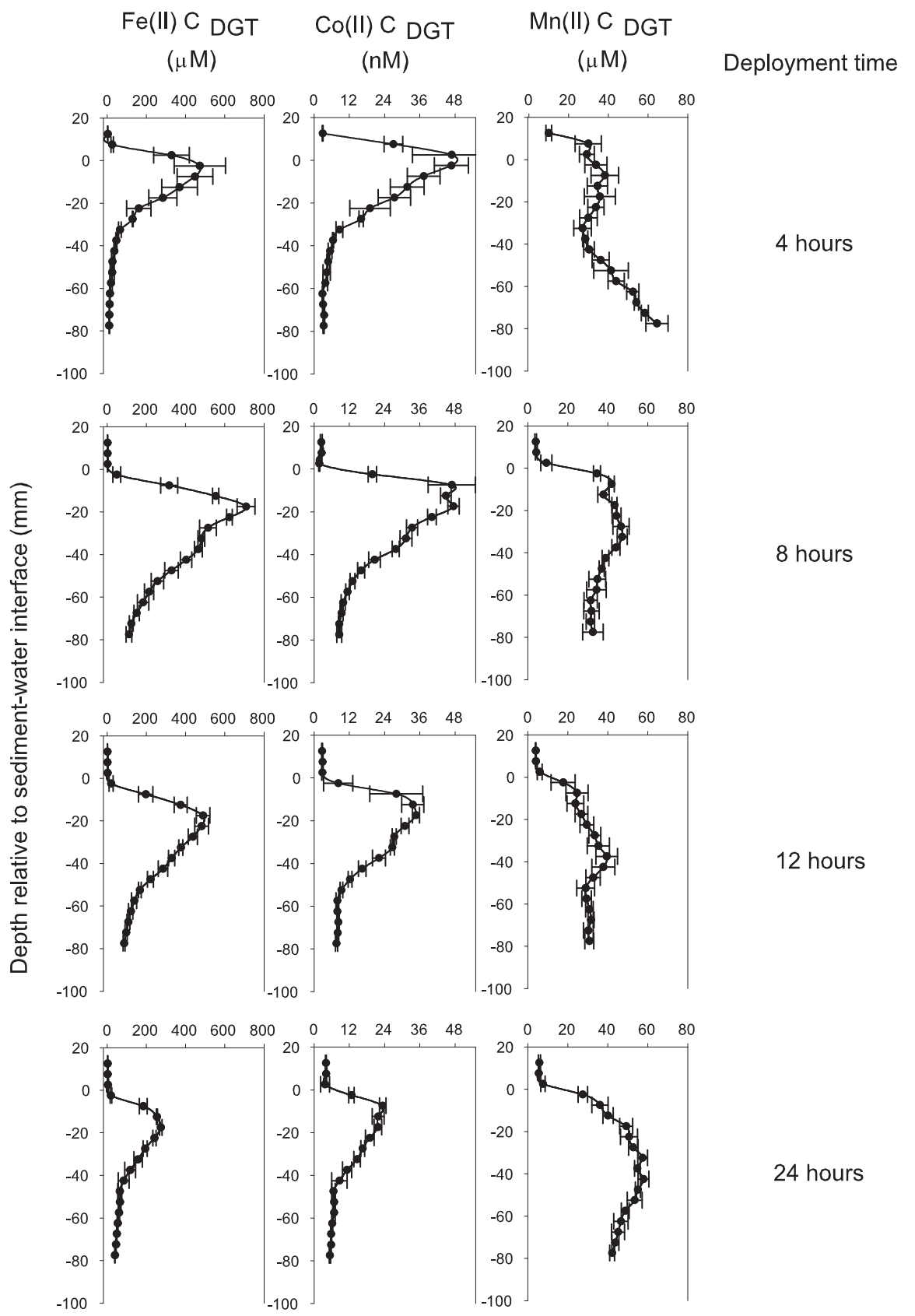

Fig. 1 Profiles of DGT concentration, $C_{\mathrm{DGT}}$ for Fe, Mn and Co obtained from four DGT deployments ( $4 \mathrm{hrs}$ to $24 \mathrm{hrs}$ ) in intact sediment cores incubated at $11^{\circ} \mathrm{C}$. Data presented are the mean values of the three gel samples for each depth, error bars are one standard deviation from the mean. Positive depths indicate data above the sediment water interface. 


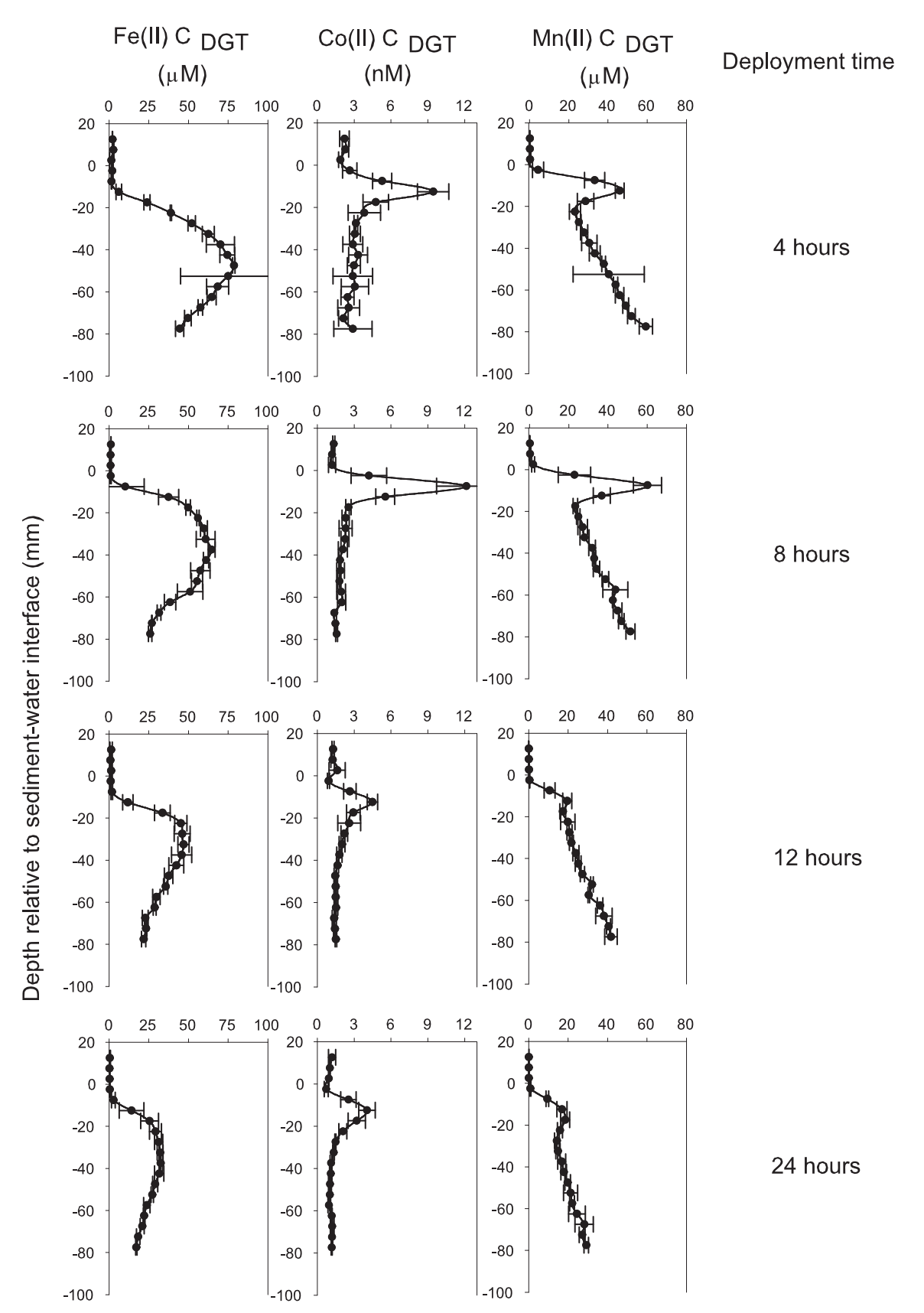

Fig. 2 Profiles of DGT concentration, $C_{\text {DGT }}$ for Fe, Mn and Co obtained from four DGT deployments (4hrs to $24 \mathrm{hrs}$ ) in homogenised, aged sediment. Data presented are the mean values of the three gel samples for each depth, error bars are one standard deviation from the mean. Positive depths indicate data above the sediment water interface. 
Table 1 Relationships between DGT concentrations $\left(\mathrm{C}_{\mathrm{DGT}}\right)$ of $\mathrm{Co}, \mathrm{Fe}$ and $\mathrm{Mn}$. Correlation coefficients $\left(\mathrm{r}^{2}\right)$ are obtained by comparing surface/peak data for the four deployments for each of the experiments. The surface-maxima are assumed to be represented by data between $\sim 10 \mathrm{~mm}$ above, to $\sim 20 \mathrm{~mm}$ and $\sim 40 \mathrm{~mm}$ below the sediment water interface for the aged and fresh sediments respectively. Peak ratios are calculated by comparing the peak values (average of the highest three values at the Co maxima) and assuming only one authigenic oxide is the source. Residual standard deviations (RSD) indicate the variability between the four different deployment times for each experiment.

\begin{tabular}{lcccc}
\hline & \multicolumn{2}{c}{ Co vs Fe } & \multicolumn{2}{c}{ Co vs Mn } \\
\hline & Aged & Intact & Aged & Intact \\
\hline $\mathrm{r}^{2}$ & 0.03 & 0.76 & 0.85 & 0.28 \\
& $(\mathrm{n}=32)$ & $(\mathrm{n}=48)$ & $(\mathrm{n}=32)$ & $(\mathrm{n}=48)$ \\
Peak ratio & - & $9.5 \times 10^{-5}$ & $1.9 \times 10^{-4}$ & $1.06 \times 10^{-3}$ \\
$\left(\mathrm{~mol} \mathrm{~mol}^{-1}\right)$ & & $(\mathrm{RSD}=8 \%)$ & $(\mathrm{RSD}=12 \%)$ & $(\mathrm{RSD}=34 \%)$ \\
\hline
\end{tabular}

similarity in the structure of the $\mathrm{Fe}$ and Co profiles indicates that these potential sources of error are not factors in these deployments.

\subsection{Comparison of the Mn, Fe and Co data}

The broad maxima in the Fe(II) profiles for the freshly collected, intact core deployment (Fig. 1) are almost coincident with the Co maxima. There is a small offset between the $\mathrm{Fe}$ and $\mathrm{Co}$ data, with the Co maxima being $\sim 1$ data point $(5 \mathrm{~mm})$ higher than that of Fe. This may be due to the difference in the oxidation rates of the reduced species of the two metals. Although, remobilisation of a different trace metal $(\mathrm{Cu})$ close to the sediment surface has been attributed to possible release from OM oxidation (Tankere-Muller et al, 2007, and references therein).

DGT concentration profiles for the aged sediment show much narrower Co maxima, coincident with similar maxima of Mn (Fig. 2). We have examined the correlation between the DGT measured concentrations of Co within the maxima with those of $\mathrm{Mn}$ and $\mathrm{Fe}$ (Table 11). The values of the correlation coefficient, $\mathrm{r}^{2}$, indicate that there is a dominant relationship between either Fe or $\mathrm{Mn}$, and $\mathrm{Co}$ in each of the experiment deployments. For the Fe dominant scenario, $\mathrm{r}^{2}$ is affected by the offset between the $\mathrm{Co}$ and $\mathrm{Fe}$ profiles. The lack of any association between $\mathrm{Fe}$ and $\mathrm{Co}$ in the aged sediment may be due to two contributing factors. 1) The peak Fe concentrations are up to 10 times lower than in the fresh sediment, which will result in a corresponding lower flux from this source. 2) The solid phase may be affected by the ageing/homogenisation process.

It is instructive to consider the geochemical processes that may affect the profiles of $\mathrm{Fe}, \mathrm{Mn}$ and $\mathrm{Co}$. These metals differ in their reactivity with sulphide and previous data from this site (Naylor et al, 2004) have shown that Mn is significantly undersaturated with respect to its sulphide phase compared to $\mathrm{Fe}$ and $\mathrm{Ni}$ (Ni has a similar degree of pyritization to Co; Morse and Luther, 1999). Loss of dissolved Co and Fe from the aged/ homogenised system may occur via formation of, or incorporation into, sulphide phases. It is likely that Co is lost via this mechanism to a greater degree than Mn, as its sulphide phase has a much lower solubility product. However, 
Mn can be removed to some extent in sulphidic systems by coprecipitation with, or adsorption to, FeS(s) (Huerta-Diaz et al, 1998). Mn is incorporated into pyrite only where there is a high degree of pyritization. Incorporation of Co into pyrite is closely related to the degree of pyrite formation (Morse and Luther, 1999). The $\mathrm{Co}-\mathrm{Fe}$ correlation in the intact cores is unlikely to be due to a direct interaction. The correlation predominantly stems from $\mathrm{Co}$ and $\mathrm{Fe}$ removal by formation of sulphides. In the intact core experiment both $\mathrm{Fe}$ and $\mathrm{Mn}$ are remobilised at the same depth, indicating that $\mathrm{Mn}$ reduction is occurring. Porewater Mn can increase with depth as its concentration is controlled more by adsorption rather than sulphide formation in the sulphate reduction zone. This work demonstrates the care that must be taken in the interpretation of regression analysis in terms of biogeochemical processes. It could have been tempting to suggest that the good correlation between peak Co and Fe in the fresh sediments indicates a direct linkage, such as reduction of authigenic Fe oxides releasing Co. However, there is probably no direct linkage and it simply reflects the similarity in their reactions with sulphide.

\subsection{Estimating the association of Co with Fe and Mn (oxyhydr)oxides}

Data on the concentrations of metal from remobilisation processes can be used to estimate the fraction of trace metal associated with the reduced authigenic oxide. This procedure has been used to obtain ratio data from Co and Mn concentrations measured in the water column of a seasonally anoxic lake (Hamilton-Tavlor et al, 2005), where a molar $\mathrm{Co} / \mathrm{Mn}$ ratio of $\sim 2.8 \times 10^{-4}$ was calculated. Lienemann et al (1997) measured these values and also compiled data from several studies of anoxic lakes, and reported values in the range $1.1 \times 10^{-4}$ to $2.6 \times 10^{-3}$. The ratios we have measured for $\mathrm{Co} / \mathrm{Mn}$ from both of our experiments are within the range of the above values (Table 1). Peak ratios we have calculated from previous DGT deployments in marine sediments are $\sim 5-8$ times higher than the (aged) value obtained in this work (Zhang et al, 2002; Fones et al, 2004). This may be due to differences in the molar fractions of Co associated with authigenic oxides in the different environments, or loss of dissolved Co from the aged/homogenised system through formation of, or incorporation into, sulphide phases. For the intact sediment the $\mathrm{Co} / \mathrm{Mn}$ value is close to the largest value cited above. Assuming there is some contribution from the authigenic $\mathrm{Fe}$, the actual $\mathrm{Co} / \mathrm{Mn}$ ratio may be slightly smaller that those reported (see below). The relatively low residual standard deviations (RSD) between the peak ratios across the 4 deployment times (Table 1 ) indicate that the replicate probes give consistent molar ratio data.

Passive sampling type techniques, such as Teflon strips and the DGT probes used in this work, calculate values from bulk processes. Estimates of trace metal association using such techniques are thus based on averaged measurements. Also, determination of the original stoichiometry of the mineral assemblage from measurements of dissolved concentrations may differ from those obtained if the solid phase were analysed. Additionally, measured dissolved concentrations may be lowered compared to the solid phase by the occurrence of side reactions (e.g. reaction with sulphide). Particles of biogenic origin isolated from the oxic waters column may have different 
formation mechanisms and kinetics than oxides formed within the oxic zone of surface sediments. Differences in the ratios of Co/Mn between water column measurements and isolated biogenic micro-particulates were reported by Lienemann et al (1997) for a freshwater system. They reported $\mathrm{Co} / \mathrm{Mn}$ ratios on micro-particulates one order of magnitude higher than ratios in the anoxic water column $(\sim 2 \%$ compared to $\sim 0.3 \%$ ). This study also reported significant concentrations of Fe associated with Mn oxides. This highlights the complexity of estimating associations of trace metals with individual oxide minerals.

It has been show that in early stages of formation manganese oxides contain many vacancies (Saratovsky et al, 2006; Petkov et al, 2009). These vacancies are the primary site for the sorption of trace metals. Furthermore, Co adsorbed to the oxide can be oxidised to $\mathrm{Co}^{3+}$ and subsequently incorporated into the oxide structure (Manceau et al, 1997). The nature of the oxides suggests that manganese oxides may have a greater fraction of associated Co than iron oxyhydroxides. For a sediment from a freshwater circumneutral lake (McFarlane, Canada) the ratio of trace metals (TM) associated independently with Mn-oxides and Fe oxyhydroxides (TM/Mn : TM/Fe) were 9.0, 2.0, 2.1, 3.8 and 0.56, for $\mathrm{Ni}, \mathrm{Cu}, \mathrm{Zn}, \mathrm{Cd}$ and $\mathrm{Pb}$ respectively (Tessier et al, 1996). Cobalt data were not obtained in their study. However, trapping of Co by manganese oxides is more efficient than the trapping of $\mathrm{Ni}$ (Shaw et al, 1990), indicating that Co ratios should be at the upper end of the range of values in the Tessier et al (1996) data. Assuming Co in the intact cores is supplied from both authigenic oxides, and that enrichment within Mn oxide is 9 times that of Fe (oxyhydr)oxide (a conservative estimate given the observations cited above), the individual molar ratios can be estimated from the peak data. Using this method we calculated ratios of $5.2 \times 10^{-5}$ for $\mathrm{Co} / \mathrm{Fe}$ and $4.6 \times 10^{-4}$ for $\mathrm{Co} / \mathrm{Mn}$. The $\mathrm{Co} / \mathrm{Mn}$ data are within the range detailed above. Fewer data exist for the ratios of $\mathrm{Co} / \mathrm{Fe}$, but our derived value is approximately half the value that can be calculated from the estuarine sediment data of Douglas and Adeney (2000), of $\sim 1.2 \times 10^{-4}$.

\section{Conclusions}

We have presented a new application of the DGT technique, namely estimation of the molar ratios of trace metal associated with authigenic Fe and Mn (oxyhydr)oxides. It exploits the fact that localized maxima in trace metals in porewaters are due to dissolution of the host solid phase. In the case presented, the Mn maxima are not visible in DGT measured concentration profiles of freshly collected sediment cores, presumably due to overlap of redox zones and rapid recycling of $\mathrm{Mn}(\mathrm{II}) / \mathrm{Mn}$-oxide in the surface layer of the sediment. After ageing of the sediment a distinct Mn peak was observed. Calculated ratios for $\mathrm{Co} / \mathrm{Mn}$ from both experiments were within the range of values cited in the literature. The value from the aged experiment was at the lower end of the range and this was attributed to loss of Co in the experimental system due to sulphide formation during the ageing period. Good correlations obtained from regression analysis were probably due to the varied processes of sulphide formation of the three metals rather than the more obvious direct linkage. The study provides additional evidence of the association of Co with oxides in sediment and demonstrates 
that $\mathrm{Co}$ is likely to be associated more with $\mathrm{Mn}$ rather than Fe oxides. To date no specific extraction schemes can specifically target a single metal oxide without extracting others. The procedure presented here allows single oxides to be targeted for extraction to a greater extent than previously reported techniques.

Future developments could include extending the range of metals analysed using this technique. The method could also be developed to assess the effect biogeochemical cycling at the sediment surface has on influencing the fate and cycling of soluble metal pollutants. This could be done by spiking the systems with dissolved metal and analysing using DGT, over several weeks or months.

Acknowledgements A. Stockdale was supported by the UK Natural Environment Research Council (NER/S/A/2005/13679). We thank Debbie Hurst for assistance with the sediment sampling and an anonymous reviewer for helpful comments that improved the manuscript.

\section{References}

Balistrieri L, Murray J, Paul B (1994) The geochemical cycling of trace elements in a biogenic meromictic lake. Geochimica et Cosmochimica Acta 58:3993-4008

Blomqvist S (1985) Reliability of core sampling of soft bottom sediment -an in situ study. Sedimentology 32:605-612

Douglas G, Adeney J (2000) Diagenetic cycling of trace elements in the bottom sediments of the Swan River Estuary, Western Australia. Applied Geochemistry 15:551-566

Ernstberger H, Davison W, Zhang H, Tye A, Young S (2002) Measurement and dynamic modeling of trace metal mobilization in soils using DGT and DIFS. Environmental Science and Technology 36:349-354

Fones G, Davison W, Hamilton-Taylor J (2004) The fine-scale remobilization of metals in the surface sediment of the North-East Atlantic. Continental Shelf Research 24:1485-1504

Garmo ØA, Davison W, Zhang H (2008) Interactions of trace metals with hydrogels and filter membranes used in DET and DGT techniques. Environmental Science and Technology 42:5682-5687

Hamilton-Taylor J, Smith E, Davison W, Sugiyama M (2005) Resolving and modeling the effects of $\mathrm{Fe}$ and $\mathrm{Mn}$ redox cycling on trace metal behavior in a seasonally anoxic lake. Geochimica et Cosmochimica Acta 69:1947-1960

Harper M, Davison W, Zhang H, Tych W (1998) Kinetics of metal exchange between solids and solutions in sediments and soils interpreted from DGT measured fluxes. Geochimica et Cosmochimica Acta 62:2757-2770

Heggie D, Lewis T (1984) Cobalt in pore waters of marine sediments. Nature 311:453-455

Huerta-Diaz M, Tessier A, Carignan R (1998) Geochemistry of trace metals associated with reduced sulfur in freshwater sediments. Applied Geochemistry $13: 213-233$ 
Lienemann CP, Taillefert M, Perret D, Gaillard JF (1997) Association of cobalt and manganese in aquatic systems: chemical and microscopic evidence. Geochimica et Cosmochimica Acta 61:1437-1446

Manceau A, Drits V, Silvester E, Bartoli C, Lanson B (1997) Structural mechanism of $\mathrm{Co}^{2+}$ oxidation by the phyllomanganate buserite. American Mineralogist 82:1150 1175

Morse J, Luther G (1999) Chemical influences on trace metal-sulfide interactions in anoxic sediments. Geochimica et Cosmochimica Acta 63:3373-3378

Naylor C, Davison W, Motelica-Heino M, Van Den Berg G, Van Der Heijdt L (2004) Simultaneous release of sulfide with $\mathrm{Fe}, \mathrm{Mn}, \mathrm{Ni}$ and $\mathrm{Zn}$ in marine harbour sediment measured using a combined metal/sulfide DGT probe. Science of the Total Environment 328:275-286

Petersen W, Wallmann K, Pinglin L, Schroeder F, Knauth HD (1995) Exchange of trace elements at the sediment-water interface during early diagenesis processes. Marine and Freshwater Research 46:19-26

Petkov V, Ren Y, Saratovsky I, Pasten P, Gurr S, Hayward M, Poeppelmeier K, Gaillard JF (2009) Atomic-scale structure of biogenic materials by total X-ray diffraction: a study of bacterial and fungal $\mathrm{MnO}_{x}$. ACS Nano 3:441-445

Saratovsky I, Wightman P, Pasten P, Gaillard JF, Poeppelmeier K (2006) Manganese oxides: parallels between abiotic and biotic structures. Journal of the American Chemical Society 128:11,188-11,198

Scally S, Davison W, Zhang H (2006) Diffusion coefficients of metals and metal complexes in hydrogels used in diffusive gradients in thin films. Analytica Chimica Acta 558:222-229

Shaw T, Gieskes J, Jahnke R (1990) Early diagenesis in differing depositional environments: the response of transition metals in pore water. Geochimica et Cosmochimica Acta 54:1233-1246

Shuttleworth S (1999) Heavy metal geochemistry in lakes: temporal and spatial variations measured with DET and DGT. PhD thesis, Lancaster University, UK

Taillefert M, MacGregor B, Gaillard JF, Lienemann CP, Perret D, Stahl D (2002) Evidence for a dynamic cycle between $\mathrm{Mn}$ and $\mathrm{Co}$ in the water column of a stratified lake. Environmental Science and Technology 36:468-476

Tankere-Muller S, Zhang H, Davison W, Finke N, Larsen O, Stahl H, Glud R (2007) Fine scale remobilisation of $\mathrm{Fe}, \mathrm{Mn}, \mathrm{Co}, \mathrm{Ni}, \mathrm{Cu}$ and $\mathrm{Cd}$ in contaminated marine sediment. Marine Chemistry 106:192-207

Tessier A, Fortin D, Belzile N, DeVitre R, Leppard G (1996) Metal sorption to diagenetic iron and manganese oxyhydroxides and associated organic matter: narrowing the gap between field and laboratory measurements. Geochimica et Cosmochimica Acta 60:387-404

Zhang H, Davison W, Gadi R, Kobayashi T (1998) In situ measurements of dissolved phosphorus in natural waters using DGT. Analytica Chimica Acta 370:29-38

Zhang H, Davison W, Mortimer R, Krom M, Hayes P, Davies I (2002) Localised remobilization of metals in marine sediment. The Science of the Total Environment 296:175-187 